Enfermagem Brasil 2018;17(5):490-6

\title{
ARTIGO ORIGINAL \\ Formação e aplicabilidade dos preceitos éticos pelos enfermeiros
}

Larissa Cristina Rodrigues Alencar*, Josafá Barbosa Marins ${ }^{* *}$, Ana Hélia de Lima Sardinha, D.Sc. ${ }^{* * *}$, Maria do Carmo Rodrigues Araújo, M.Sc. ${ }^{* * *}$

${ }^{*}$ Enfermeira, Mestranda em Enfermagem pela Universidade Federal do Maranhão (UFMA), ${ }^{* *}$ Enfermeiro, Mestrando em Enfermagem pela UFMA, ${ }^{* * *}$ Enfermeira, Docente do Departamento de Enfermagem da UFMA, ${ }^{* * *}{ }^{*}$ Enfermeira, Doutoranda em Políticas Públicas pela Universidade Federal do Maranhão, Docente do Departamento de Enfermagem da UFMA

Recebido em 18 de janeiro de 2018; aceito em 2 de julho de 2018.

Endereço para correspondência: Larissa Cristina Rodrigues Alencar, Alameda V, Condomínio Torre do Sol, Bloco K/402 Bequimão 65061-000 São Luís MA, E-mail: laracr.alencar@hotmail.com, Josafá Barbosa Marins: j_ufma20@hotmail.com; Ana Helia de Lima Sardinha: anahsardinha@ibest.com.br; Maria do Carmo Rodrigues Araujo: mdcra@oi.com.br

\section{Resumo}

Introdução: $\mathrm{Na}$ área da saúde, a competência ética dos futuros profissionais é entendida como a capacidade autônoma de percepção, reflexão e decisão coerente em relação às condutas humanas no cuidado à saúde e à vida. A enfermagem vem se desenvolvendo com base em conhecimentos empíricos, teorias fundamentadas e desempenho dirigido à assistência, ao ensino, ao gerenciamento e à pesquisa. Objetivo: Apreender as percepções dos enfermeiros de um Hospital Universitário acerca da formação e aplicabilidade dos preceitos éticos na profissão. Material e métodos: Pesquisa, qualitativa descritiva, realizada em um Hospital Universitário em São Luis/MA. Realizaram-se entrevistas semiestruturadas com 30 enfermeiros, as quais foram examinadas através da técnica de análise de conteúdo. Resultados: Emergiram 4 categorias: a) Ensino da ética; b) Postura ética dos enfermeiros; c) Relacionamento com a instituição; d) Domínio ético dos profissionais. Conclusão: Faz-se necessário o entendimento da importância da ética na enfermagem, seja esta na assistência ou no ensino, atrelada aos valores adquiridos na formação social, familiar, religiosa, inerentes ao indivíduo.

Palavras-chave: ética, enfermagem, ensino, assistência.

\section{Abstract}

Training and applicability of ethical precepts by nurses

Introduction: In the area of health, the ethical competence of future professionals is understood as the autonomous capacity for perception, reflection and coherent decision in relation to human behaviors in health care and life. Nursing has been developing based on empirical knowledge and grounded theories and multiple professional activities focused on care, teaching, management and research. Objective: To apprehend the nurses' perceptions from a University Hospital about the formation and applicability of the ethical within the profession. Methods: Qualitative and descriptive research, performed at the University Hospital in São Luis/MA. We used a semi-structured interview with 30 nurses. The speeches were examined by content analysis technique. Results: Four categories emerged: a) Ethics education; b) Ethical posture of nurses; c) Relationship with the institution; d) Ethical domain of nurses. Conclusion: It is necessary to understand the importance of ethics in nursing, in teaching or assistance, linked to the values acquired in the social, family and religious formation inherent to the individual.

Key-words: ethics, nursing, instruction, care.

\section{Resumen}

Formación y aplicabilidad de los preceptos éticos por los enfermeros

Introducción: En el área de la salud, la competencia ética de los futuros profesionales es entendida como la capacidad autónoma de percepción, reflexión y decisión coherentes en relación a las conductas humanas en el cuidado de la salud y la vida. La enfermería viene desarrollándose con base en conocimientos empíricos, teorías fundamentadas y desempeño dirigido a la asistencia, enseñanza, gestión y a la investigación. Objetivo: Aprehender las 
percepciones de los enfermeros de un Hospital Universitario acerca de la formación y aplicabilidad de los preceptos éticos en la profesión. Material y métodos: Investigación, cualitativa descriptiva, llevada a cabo en un Hospital Universitario en São Luis/MA. Se realizó una entrevista semiestructurada con 30 enfermeros. Las entrevistas fueron examinadas a través de la técnica de análisis de contenido. Resultados: Emergieron 4 categorías: a) Enseñanza de la ética; b) Postura ética de los enfermeros; c) Relación con la institución; d) Dominio ético de los profesionales. Conclusión: Se hace necesario el entendimiento de la importancia de la ética en la enfermería, sea ésta en la asistencia o en la enseñanza, vinculada a los valores adquiridos en la formación social, familiar, religiosa, inherentes al individuo.

Palabras-clave: ética, enfermería, enseñanza, asistencia.

Introdução

A ética vem sendo alvo de estudos e tem sido tradicionalmente analisada por filósofos, desde o tempo dos gregos clássicos. A palavra ética vem do grego ethos, que significa hábito ou costume. É o domínio da filosofia responsável pela investigação dos princípios que orientam o comportamento humano. Ou seja, que tem por objeto o juízo de apreciação que distingue o bem e o mal, o comportamento correto e o incorreto [1].

$\mathrm{Na}$ área da saúde, a competência ética dos futuros profissionais é entendida como a capacidade autônoma de percepção, reflexão e decisão coerente em relação às condutas humanas no cuidado à saúde e à vida. $\mathrm{O}$ desenvolvimento dessa competência requer docentes capacitados e dispostos a assumir a discussão de aspectos relativos à prática educativa, de modo a favorecer uma formação centrada no educando e qualificada para a sociedade [2].

Diante dos avanços da tecnologia e a previsão legal de atuação em atividades de maior complexidade técnica, é necessário o investimento deste profissional em capacitação constante, abrindo-se um amplo espaço de atuação ao enfermeiro [3].

A construção de espaços éticos exige ambientes que ofereçam espaços para a voz, para o discurso, substituindo o silencio dos problemas morais vivenciados. A dimensão ética presente no ambiente de trabalho, na maioria das vezes, não é objeto de discussão e acaba tornando-se um tema negado, negligenciado, apesar de sua importância na atuação do profissional [4].

As profissões da saúde passam atualmente por reorientação da formação acadêmica em busca de um perfil de egressos capacitados a uma assistência humanizada, de alta qualidade e resolutividade. Neste contexto, um desafio central e envolve a formação ética de seus estudantes para o desenvolvimento de competências profissionais e, ao mesmo tempo, de cidadãos prudentes, responsáveis e socialmente comprometidos [5].

Para os profissionais de Enfermagem, a ética é fundamental, seja na assistência, docência ou no gerenciamento dos serviços. Tendo em vista a importância da temática no ensino e na prática da enfermagem o profissional deve buscar estratégias para resolução de problemas que podem emergir. Este estudo objetivou apreender as percepções dos enfermeiros de um Hospital Universitário acerca da formação e a aplicabilidade dos preceitos éticos dentro da profissão de Enfermagem.

\section{Material e métodos}

Trata-se de uma pesquisa descritiva, exploratória com abordagem qualitativa realizada em um Hospital Universitário (HU) no município de São Luis/MA, no período de janeiro a julho 2016. Foram entrevistados 30 enfermeiros atuantes no hospital, independente do setor, com agendamento prévio.

Como critérios de inclusão encontram-se os enfermeiros que atuavam na instituição e aceitaram participar do estudo respeitando a resolução vigente. Dentro dos critérios de exclusão, encontram-se aqueles enfermeiros que se recusaram a assinar o Termo de Consentimento Livre e Esclarecido (TCLE), aqueles que não estavam presentes por motivo de férias ou afastamento durante a realização das entrevistas.

Os dados foram coletados por meio de entrevista semiestruturada, as questões norteadoras foram: Ao sair da sua instituição formadora você se sentiu com conhecimento ético suficiente para prestar assistência? Se houveram, quais foram as dificuldades? Como você avalia a estimulação de práticas éticas por parte da instituição? Fale a respeito da postura ética dos enfermeiros na instituição. Seu relacionamento com a instituição e outros profissionais é 
positivo ou negativo? Descreva como este se dá. Como você avalia seu domínio ético para a resolução de conflitos que surgem no ambiente de trabalho?

As entrevistas foram gravadas com auxílio de MP4 e transcritas integralmente. A categorização e interpretação das falas foram realizadas por meio da análise do conteúdo das respostas. A análise de conteúdo é um conjunto de técnicas de análise de comunicação, visando obter por procedimentos sistemáticos e objetivos de descrição do conteúdo das mensagens que permitam a inferência de conhecimentos relativos às condições de produção $e$ recepção destas mensagens [6]. A partir desta análise emergiram as seguintes categorias: Ensino da ética, Postura ética dos enfermeiros, Relacionamento com a instituição, Domínio ético dos Profissionais.

Para preservar o sigilo e anonimato dos entrevistados, utilizou-se indicador alfanumérico ( $E 1$ a $E 30)$. A pesquisa obedeceu às normas da resolução 466/12 do Conselho Nacional de Saúde e foi apreciada pelo Comitê de Ética em Pesquisa (CEP) da UFMA e aprovado com parecer consubstanciado $n^{\circ} \mathbf{1 . 5 0 2 . 3 6 3 . ~}$

Resultados

Em relação ao perfil dos enfermeiros, 26 eram do sexo feminino e 4 do sexo masculino e a idade variou de 18 a 46 anos; tempo de formados entre 1 e 21 anos; tempo de atuação na assistência de um a 20 anos; quanto as titulações 25 possuíam especialização, 2 possuíam mestrado e 3 não possuíam nenhuma especialização.

As percepções dos enfermeiros sobre a formação e a aplicabilidade dos preceitos éticos dentro da profissão de Enfermagem foram agrupadas em quatro categorias de análise, como seguem:

\section{a) Ensino da ética}

Todos os enfermeiros obtiveram durante a graduação, uma disciplina voltada para o ensino da ética, como previsto nas Diretrizes Curriculares Nacionais (DCNs) e preconizado pelo Conselho Nacional de Saúde (CNS). Porém nem sempre os objetivos são alcançados após a disciplina.

E15: "A disciplina de ética foi ofertada no começo do curso, mas, em minha opinião, ela foi bastante teórica, se tornou cansativa com aquelas leituras [...]".

A forma com que a ética foi trabalhada deixou lacunas no processo de formação do profissional, levantando sugestões para tal ensino.

E4“[...] a Disciplina de ética deveria abordar temas práticos e não somente teóricos [...]”.

A metodologia de ensino utilizada no ensino da ética torna o enfermeiro mais capacitado e apto, fato este que pode auxiliar na tomada de decisões no exercer da profissão.

E1: "Minha graduação foi bastante proveitosa; e a pedagogia foi a problematizadora o que facilitou na minha carreira profissional [...]".

Percebe-se a necessidade existente nos discursos dos enfermeiros quanto à aplicabilidade dos conhecimentos éticos, estando associada a pouca importância que é dada a temática durante a formação. A disciplina de ética poderia estar presente em mais períodos, pois abrange toda a área de atuação da categoria.

E2 "[...] A Disciplina de ética deveria ser em mais períodos; não somente em um".

\section{b) Postura ética dos enfermeiros}

Destaca-se nos relatos dos enfermeiros que os seus colegas de profissão possuem uma boa postura, no que tange a resolução de conflitos, enfretamento de questionamentos junto ao paciente e a equipe multidisciplinar. 
E9: "Geralmente o relacionamento interpessoal nesse setor é bom, pois os profissionais são cientes do código de ética da Enfermagem e respeitam esse código [...]".

Por outro lado, alguns enfermeiros possuem uma percepção negativa acerca da postura de seus companheiros, como podemos observar nos trechos abaixo:

E7: "Alguns profissionais não tem ética com colegas de profissão e nem com os pacientes".

E13:"Existem profissionais que não exercem a ética profissional em seu trabalho, infelizmente".

E 15: "[...] presenciei atitudes que o próprio código de ética abomina"

E 19: "[...] não observo por parte da maioria uma postura adequada com seus subordinados e vice-versa".

\section{c) Relacionamento com a instituição}

Todos os enfermeiros afirmaram possuir um relacionamento positivo com a instituição, no que diz respeito ao cumprimento de normas, resolução de conflitos, comunicação com superiores entre outras questões. Este depoimento associa o bom relacionamento à prestação de uma assistência de qualidade.

E17: "[...] A relação é de comprometimento com politica de qualidade, evidenciado pelas opiniões sobre os serviços e bom atendimento prestado aos usuários".

Porém reconhece-se em alguns discursos a necessidade em aperfeiçoar os métodos de ensino e estimulação de práticas éticas por parte da instituição.

E15: "Quando já temos muito tempo de formados e temos uma dúvida, pensamos a quem recorrer nessas situações. Os hospitais poderiam dar mais apoio ao profissional e oferecer espaços para discussão do tema, esclarecendo dúvidas e ajudando a gente a tomar decisões".

Pode-se perceber que uma postura ética adotada por outros profissionais, da própria empresa ou sistema de saúde influencia o comportamento e a tomada de decisão dos enfermeiros. Como podemos observar no discurso do participante E7 que citou como dificuldades: "A organização do serviço/Sistema de saúde. Não colaboração de outros profissionais". E11: "Há necessidade de uniformizar, divulgar as práticas éticas dentro da instituição".

\section{d) Domínio ético dos profissionais}

A percepção dos profissionais é de que cursos de especialização e a experiência adquirida atuam como capacitação secundária à graduação.

E1: "Fiz alguns cursos de liderança e conflitos em ambiente de trabalho, isso me ajuda muito a mediar conflitos [...]".

E6: "Acredito que a cada dia temos novos aprendizados com as situações que enfrentamos. $\mathrm{O}$ trabalho ético é uma construção diária [.]."

E9: "Dependendo da situação sempre surgem dúvidas, mas procuro buscar o conhecimento necessário para resolvê-las".

Porém muitos enfermeiros afirmam não possuir conhecimento adequado acerca do Código de Ética dos Profissionais de Enfermagem (CEPE), bem como dificuldades na prática.

E7: "Deficiência no conhecimento de todo Código de Ética".

E11: "Falta de segurança para aplicação de alguns conhecimentos".

Discussão

Percebeu-se, neste estudo, que a pouca importância dada por parte das instituições de ensino e hospitalares à temática da ética, durante a formação dos profissionais, faz com que surjam dúvidas no desempenho das atividades, o que pode comprometer a qualidade da 
assistência. Isto leva o profissional a buscar novas estratégias para suprir tal deficiência, que incluem capacitações, apoio das instituições e embasamento na experiência adquirida.

Como previsto nas DCNs, os profissionais devem realizar seus serviços dentro dos mais altos padrões de qualidade e dos princípios da ética/bioética, tendo em conta que a responsabilidade da atenção à saúde não se encerra com o ato técnico, mas, sim, com a resolução do problema de saúde, tanto em nível individual como coletivo [7]. Porém o ensino da ética assume uma realidade muito distante do ideal e esperado pelos profissionais.

A construção do ensino da ética na graduação deve ser pautada em discussões teóricas-práticas para que os alunos desenvolvam uma visão crítica e possuam conhecimentos e habilidades necessárias para a resolução de problemas.

A temática faz parte do currículo, todavia mesmo perante a importância dessa disciplina, muitas das vezes não recebe a devida atenção enfatizando somente questões técnicas e práticas. Os conteúdos são na maioria das vezes descontextualizados da prática real e não permitem a criação de espaços para reflexão necessários à decisão e conduta competente [8].

Tendo em vista dinamicidade que é o processo de construção e formação da sociedade atual, faz-se necessário que ocorra uma adaptação do modo de vida às transformações técnicas e científicas, bem como na forma de ensinar um conteúdo tão transversal.

Ao questionar o ensino da ética na enfermagem, vale ressaltar que a ética, na formação profissional, busca refletir criticamente sobre o comportamento humano, trata da interpretação, discussão, problematização de valores e princípios [9]. Baseado neste pensamento crítico as metodologias utilizados no ensino permitem a concretização das discussões teóricas à prática da profissão. $O$ uso de metodologia ativa de ensino facilita 0 aprendizado e contribui positivamente para este processo.

Nessa linha de raciocínio, diversos autores afirmam que a ética deve ser inserida de maneira mais consistentes nas diversas áreas de formação do enfermeiro como se pode observar nos estudos publicados. Apesar de organizada em conteúdos específicos, a ética foi apontada pelos professores como tema transversal, que permeia todo processo de formação dos alunos de graduação em enfermagem. Dessa forma, a inclusão da discussão ética em todos os assuntos da teoria e da prática configura-se como principal estratégia para o ensino [10].

Neste ponto é fundamental compreender como ocorre a inserção da temática em questão no ensino voltado para a graduação. A ética é trabalhada de forma direta em apenas uma disciplina, segundo comentários dos participantes do estudo. Esta disciplina ofertada nos primeiros períodos do curso discute de forma teórica alguns conceitos e os mesmos não são aplicados nas outras disciplinas ao decorrer do processo de formação.

Uma conduta ética adequada é associada a um bom relacionamento interpessoal. $\mathrm{O}$ respeito ao Código de ética em vigor, torna-se fundamental dentro do ambiente de trabalho. Um bom comportamento ético além de garantir uma assistência com segurança $e$ responsabilidade, faz com que o ambiente em si torne-se favorável para a troca de relações, o que é fundamental quando se trabalha em equipe. Em todas essas trocas os princípios éticos deverão ser levados em consideração.

Associa-se uma adequada conduta ética ao conhecimento Código de Ética dos Profissionais de Enfermagem. O CEPE respalda a profissão em suas diferentes vertentes, observa-se que este flexibiliza a prática profissional no exercício das diversas áreas de atuação da Enfermagem. Os profissionais deverão, ainda, tê-lo como norteador na orientação e segurança para o exercício da enfermagem com qualidade e dignidade humana [11].

A maioria das inadequações relacionadas aos profissionais está relacionada com o sigilo de informações que lhes cabe. O dever ético e legal dos profissionais de saúde tem origem justamente na garantia da privacidade e confidencialidade das informações dos pacientes, mantendo, desse modo, o sigilo das informações. O segredo profissional no trabalho de assistência à saúde é evidenciado no pensamento hipocrático [12]. Tal postura adotada pelos enfermeiros pode prejudicar a qualidade da assistência que é prestada e dificultar 0 relacionamento entre a equipe.

A postura ética dos profissionais é influenciada pelo seu processo de formação, pelo incentivo da instituição ao qual os mesmos estão inseridos, esta união reflete na prática da profissão, no relacionamento interpessoal e nas tomadas de decisões. Observa-se falta de ética nos profissionais, relacionadas ao sigilo de informações segundo comentários dos 
participantes do estudo. Estes profissionais devem ser estimulados e conscientizados sobre condutas éticas e a importância destas na prática da profissão.

Os profissionais de saúde de maneira geral têm responsabilidades éticas com a dignidade humana dos pacientes, por meio de medidas adotadas no desempenho de suas funções [13]. O fato de se trabalhar com vidas torna os enfermeiros conscientes da responsabilidade que possuem durante o exercer da profissão, este tipo de atitude é um aspecto positivo e auxiliador da conduta dos mesmos.

As instituições de saúde por outro lado, também possuem suas responsabilidades no que diz respeito à oferta de condições de trabalho favoráveis e isto inclui um serviço de educação continuada, além dos recursos humanos e materiais adequados. Uma medida adotada é criação de Comitês de Ética em hospitais para deliberar as decisões em situações de conflitos, associando ainda a incorporação de profissionais especialistas em bioética ao quadro de profissionais para atuarem diretamente com os pacientes e com as equipes [13].

Cabe as instituições, sejam estas públicas ou privadas, identificar as dificuldades dos profissionais e propor estratégias de enfrentamento que reflitam na prática dos profissionais de forma positiva. Este processo se dá por meio de um Núcleo de Educação Continuada empenhado a suprir as necessidades dos colaboradores. Aliado a este processo institucional percebe-se que os profissionais com mais experiência possuem melhor manejo frente as questões éticas, desta forma observa-se que a vivência na profissão torna os enfermeiros mais seguros para agir baseados nos preceitos éticos.

Ao identificar as atividades desenvolvidas pelos profissionais de enfermagem, verificouse a necessidade de reafirmar a questão educativa como compromisso com o crescimento pessoal e profissional, visando a melhoria na qualidade da prática profissional. Constata-se que, no contexto da formação e do desenvolvimento profissional, tal questão pode ser percebida sob diferentes vertentes, tais como: educação permanente, educação em serviço e educação continuada [14].

No cotidiano de trabalho, o enfermeiro é mediador da equipe de saúde diante de situações conflituosas e utiliza várias estratégias para lidar com essas situações. Entretanto, esse profissional muitas vezes apresenta dificuldades em lidar com o conflito organizacional, de forma coletiva, ou seja, promovendo espaços para que os profissionais, principalmente da enfermagem, tenham oportunidades de analisar seus conflitos conjuntamente [15].

As dificuldades encontradas pelos profissionais acabam refletindo na assistência e no relacionamento com a equipe multidisciplinar, estratégias para suprir tais necessidades devem ser desenvolvidas pela instituição e pelos profissionais. Atrelado à educação continuada a categoria deve conscientizar-se da importância que esse tema possui no âmbito da Enfermagem, pois permeia todo o exercício da profissão, e muitas das vezes acaba sendo negligenciado pela pouca atenção recebida desde a graduação.

As limitações deste estudo foi o fato das fontes geradas pelas entrevistas dos enfermeiros serem carregadas de emoção e influenciadas por experiências anteriores e o fato de algumas entrevistas serem realizadas no ambiente de trabalho, o que pode impedir total entrega do profissional para discutir sobre suas subjetividades. Entretanto, as transcrições poderão fornecer base para mais estudos em relação a essa temática.

Compreendeu-se que os enfermeiros possuem necessidades de aprofundamento e manejo adequado das questões éticas, bem como o pouco preparo que estes recebem durante a graduação para o enfrentamento que a prática da profissão exige. Foi possível constatar que a experiência profissional e capacitações contribuíram positivamente na adoção de uma adequada postura ética, pois frente aos desafios o enfermeiro busca conhecimento e formas de aprender para desenvolver suas atividades com maior êxito.

Faz-se necessário salientar o papel que as instituições de ensino possuem ao propiciar um ambiente adequado para o ensino da ética, por meio de discussões e inserção da temática durante todo o processo de formação. O uso de metodologias ativas de ensino permite ao aluno maior reflexão e melhor aplicação dos conhecimentos adquiridos à prática da profissão. Uma boa base acadêmica gera um egresso mais preparado e capacitado para atuar segundo os preceitos éticos da enfermagem.

O sistema de saúde e as instituições hospitalares, sejam estas públicas ou privadas, tem responsabilidade no que diz respeito a oferta de recursos para atuação dos profissionais e garantia de uma prática profissional segura. Diversas atividades podem auxiliar os profissionais 
a um melhor manejo, como discussões de caso e serviços de Educação Continuada envolvendo a temática da ética.

Os enfermeiros de modo geral percebem a importância da ética na profissão, porém identificam-se lacunas na formação destes profissionais e dificuldades após inserção no mercado de trabalho. Tais dificuldades são reflexo do processo de formação e pouca importância dada a temática pelas organizações.

É fundamental destacar que a formação ética ocorre principalmente no âmbito social de cada indivíduo, e se configura como uma construção diária. As instituições sociais principalmente a família e a religião, quando presentes, contribuem fortemente na constituição do caráter de cada um. Essa construção possui fortes reflexos na atuação profissional, independente da área que este siga.

\section{Agradecimentos}

Os agradecimentos vão direcionados à Universidade Federal do Maranhão e aos enfermeiros do Hospital Universitário Presidente Dutra por colaboração e realização deste estudo.

1. Carapeto C, Fonseca F. Ética e deontologia - Manual de formação. Lisboa: Ordem dos Engenheiros Técnicos (OIT): Lisboa; 2012. 8 p.

2. Gerber VKQ, Zagonel IPS. A ética no ensino superior na área da saúde: uma revisão integrativa. Rev Bioética 2013;21(1):168-78.

3. Mattozinho FC, Freitas GF. Ocorrências éticas de enfermagem no Estado de São Paulo: descrição fática. Acta Paul Enferm 2015;28(6):593-600.

4. Lunardi VL, Filho WDL, Silveira RS, Silva PA, Mancia JR. Gestão de enfermagem e construção de ambientes éticos. Enferm Foco 2016;7(3/4):41-5.

5. Finkler M, Caetano JC, Ramos FRS. Ética e valores na formação profissional em odontologia: um estudo de caso. Ciênc Saúde Coletiva 2013;16(11):4481-92.

6. Bardin L. Análise de conteúdo (L. de A. Rego \& A. Pinheiro, Trads.). Lisboa: Edições 70; 2015.

7. Conselho Nacional de Educação. Câmara de Educação Superior. Resolução CNE/CES 3/2001. Diário Oficial da União, Brasília, 9 de Novembro de 2001. Seção 1, p. 37.

8. Silva ALNV, Freitas AF. Ensino da ética e legislação profissional em um curso técnico de enfermagem: relato de experiência. Saúde Redes 2016;2(4)Suplemento.

9. Crozeta K, Stocco JGD, Labronici LM, Méier MJ. Interface entre a ética e um conceito de tecnologia em enfermagem. Acta Paul Enferm 2010;23(2):239-43.

10. Ramos FRS, Brehmer LCF, Vargas MAO, Schneider DH, Drago LC. A ética que se constrói no processo de formação de Enfermeiros. Rev Latinoam Enferm 2013;21:1-9.

11. Silva RS, Santos DT, Carvalho SS, Lisboa ACFN. Código de ética dos profissionais de Enfermagem: uma pesquisa documental. Rev Oficial Conselho Enferm 2012;3(2):62-6.

12. Dias OV, Gomes LMX, Barbosa TLA, Souza LPS, R ALF, Costa SM. Segredo profissional e sua importância na prática de enfermeiros e odontólogos. Revista Bioética 2013;21(3):448-54.

13. Goldim JR, Francisco CF. Os Comitês de ética hospitalar. Revista Bioética 2009;6(2).

14. Paschoal AS, Mantovani MF, Lacerda MF. A educação permanente em enfermagem: subsidios para a prática profissional. Rev Gaúch Enferm 2006;27(3):336-43.

15. Spagnol C. Situações de conflito vivenciadas no contexto hospitalar: a visão dos técnicos e auxiliares de enfermagem. Rev Esc Enferm USP 2010;44(3):803-11. 